\title{
Becoming Gamesworkers: Diversity, Higher Education, and the Future of the Game
}

\section{Industry}

Over the last decade, there has been increasing focus on the necessity of higher education (HE) training to secure careers in game development. For example, in a March 2017 Guardian article reporting on diversity problems in the game industry, the CEO of UK games trade body TIGA, Richard Wilson, justified employment inequalities by saying:

The video games industry depends upon highly skilled, highly talented and highly qualified people to create games. Typically, $80 \%$ of the workforce is qualified to degree level or above, but the proportion of women studying subjects such as computer science or games programming courses is low. There is only a comparatively small pool of potential female employees available to work in the games industry (Wilson quoted in Ramanan 2017).

Governmental data on gender-based pay disparities, highlighting pronounced differences between wages paid to men and women in the UK game industry, is similarly explained by Wilson as a matter of supply based on educational gaps (Taylor 2018). This positioning of formalized training as the rationale for low numbers of women in the industry, as well as discrepancies in reward when in the workforce, conflicts with previous explanations for their underrepresentation and marginalization in this industry. As Mark Deuze et al. (2007) note, formal games HE has only recently joined game testing, modding, and networking as a crucial route to finding work in mainstream game production. Such informal routes into professional game labor, premised on gaming capital and exclusionary social networks, were also used to explain and justify patterns of male domination in the industry, and inspired many of the tactics of advocates and activists organizing alternative tools and informal educational initiatives for 
marginalized groups to make games (see Fisher and Harvey 2013; Harvey and Shepherd 2016). Privileging formalized training therefore could present a challenge to independent, alternative, experimental, and community initiatives supporting inclusivity measures by locating the sole site of acceptable skills development within Higher Education Institutions (HEI), a move that in the UK represents at minimum a significant financial barrier.

This article is based on qualitative research of video game courses of study within UK HEI aimed at understanding the challenges and potential opportunities for greater inclusion in gameswork afforded by the growing emphasis on formalized education in games. Is it possible, despite the high costs of tuition, that this new entryway into gameswork may represent a means of shifting the industry's "hegemony of play" (Fron et al. 2007) by providing a more broadly accessible arena for developing the skills and knowledge required for gameswork? Does HE training reconfigure the constellation of gaming capital (Consalvo 2007) self-taught approaches such as modding require and therefore afford greater opportunities for those marginalized in the status quo of games, particularly female-identified individuals, people of color, and LGBTQ groups to enter and be recognized in the field? This is certainly implied by the rhetoric in education and work policy in the UK game development context, which suggests a relationship between inclusion and the university, with HE identified as a centrally important mechanism for developing and supporting diverse talent in a national context where women currently constitute only nineteen percent of the game workforce (Densham 2016).

Granular data about the demographics of game HE are not provided by the Higher Education Funding Council for England. Given how these programs engage in training that blends the discretely categorized subject areas of computer science and art and design, it is 
impossible to get a sense of whether low numbers of women in the latter and their increasing enrolment in the former is instructive about diversity in game HE. According to research by Creative Skillset cited by the trade body UKIE (2015), women comprised twenty-nine percent of those enrolled on game courses in 2014, which indicates a high degree of attrition when compared to the gender breakdown in the UK game industry. Compounding the issue is that there is yet no research on how gender intersects with race, ethnicity, class, sexuality, and ability in this context. These gaps motivate the research as much as the discourse framing HE as the locus of equalization of talent development in games. This analysis is part of the larger research project ReFiguring Innovation in Game, led by Professor Jennifer Jenson, which aims to 'create equity' (Jenson and de Castell 2013) through interventions into games industry, culture, and informal as well as formal education internationally. It offers the first insights into challenges and opportunities within the culture and structure of games HE for pursuing action for change related to inequalities.

Looking towards $\mathrm{HE}$ as the route to work and addressing inequality resurrects familiar metaphors from pre-existing discussions of gender disparities in STEM education and work. In particular, major game trade and skill groups in the UK, from UKIE to the UK Games Fund, reference a familiar image in discussing a "game talent pipeline." Pipeline discourse is friendly to government funding as the example of the well-subsidized and widely-promoted talent development program Tranzfuser, announced in 2016 and aimed at recent graduates, demonstrates:

Tranzfuser is the first talent programme brought to you by UK Games Talent aiming to provide an annual shot of top talent into the UK development ecosystem with a particular focus on creative team leaders of the future. It looks to supply a pipeline to 
enterprise and/or employment recognition for new UK games graduates, taking teams from concept and prototyping through to publishing. (Transfuzer About Us Page 2018)

Within research on STEM, the pipeline metaphor has been roundly critiqued for failing to account for the range of factors that can obstruct students, graduates, and employees in their pursuits, including intersectional barriers in what are largely white, male cultures (Carlone and Johnson 2007). It evokes a vision whereby if enough force is imposed at one end of the pipeline — be it pumping entrants in or "priming" students for employability — students will inevitably be propelled towards success. As a mechanistic approach to understanding education and work trajectories, it affirms a singular, normative direction for students, graduates, and employees to take, reifying the authoritative position of HEIs in this configuration rather than multiple potential pathways, including diverse points of entry, midcareer attrition, and varied working histories. Finally, HEIs have been poor overall at addressing institutional and structural forces, which disproportionately impact underrepresented and marginalized people in STEM. In this article, I examine the context this policy and industry rhetoric refers to, expanding the critical analysis of game education conducted by Daniel Ashton (2009a; 2009b) in the UK and Owen Livermore (2009) in Canada, both of whom indicate the significance of "work-readiness" aligned with shifting market demands for students, instructors, and HEI. I focus specifically on how these visions shape gamesworker subjectivities, fostering a masculinized labor bravado that normalizes exploitation and precarity in work while conflicting with creativity and the cultivation of greater diversity and inclusivity in games.

\section{Methods}


In the context of renewed interest in talent pipelines, an analysis of the grounded realities of those implicated in this heightened rhetoric related to game talent, diversity, and HE enables new insight into how educational experiences are structured and experienced. This study draws on forty-nine in-depth, semi-structured interviews with students, instructors, and administrators in a range of UK game programs across five universities. Participants came from a diverse range of degrees, both undergraduate and postgraduate, in areas including programming, art, design, technology, business, and critical theory, among others. These interviews were complemented with tours of facilities, including labs, offices, studios, and student exhibitions, which allowed for observations of participants' working conditions, in-progress projects, and spatial dynamics. Interview questions covered themes including gameplay, educational, and work backgrounds, courses taken or taught, experiences with employability initiatives and industry participation in the program, culture of the student body and program, and future plans. The conceptual questions probed by this analysis, related to diversity in education, work, and games as well as innovation, industry norms, and widening markets, were asked at the end of the interview and in as neutral terms as possible. Direct engagement with respondents on these topics was important to gain a sense of their explanations for contemporary trends and the discourses mobilized in response to challenges and opportunities in this area. Participants were often eager to take a strong position on these topics and yet simultaneously reluctant at times to discuss their personal experiences in this regard. Such reticence is not uncommon in research on inequalities, where "hesitancy to identify such issues is bound up with the centrality of neoliberal discourses to processes of subjectification where to position oneself through discourses of inequality invites the danger of being seen as inadequate" (Allen et al. 2013, 435). 
Despite the emphasis in the invitation to participate on students from diverse backgrounds, the majority of participants in the study were white British or Central European males. In total, sixteen participants identified as female and/or selected their preferred pronoun as "she," and five non-European students and instructors participated in the study. One participant described his educational experience as shaped by physical disability, and several others discussed the impact of learning disabilities and neurodivergence as relevant to their time in the program. While questions of sexuality and gender identity were not explicitly posed, seven students disclosed being lesbian, gay, bisexual, trans*, or genderqueer, again in the context of the relationship between their thoughts on diversity, education, work, and games. Less visible forms of diversity therefore may very well be more prevalent in spaces of game HE that appear on the surface to be largely homogenous.

Interviews were analyzed thematically to gain insight into the repertoires participants drew on in explaining their perspectives, choices, and plans. These ideas were set into conversation with printed and web marketing materials for each HEI under study as well as six others. Promotional documents beyond the case study institutions were selected to ensure the anonymity of the participating institutions, and to also gain a sense of discursive trends across the range of programs, institutions, and local contexts in the UK. These promotional materials are interesting not in terms of whether they reflect the reality of student experiences or outcomes but in the promises they make, the students, careers, and industries they imagine, and subjectivities and practices they performatively highlight. Lynne Pettinger et al. $(2016,7)$ argue that HEI promotional materials are "semiotic devices" connoting "structures of feeling that link together workplace and classroom, origins and destinations of students." Interviews were also set in conversation with policy and lobby documents related to the UK game industry, education, 
talent development, and diversity, with materials collected from TIGA, UKIE, Creative Skillset, NESTA, and NextGen Skills Academy, among others. In what follows I consider the barriers to participation represented by the talent agenda, particularly in how it locates inclusivity and diversity within game HE, by focusing on the gamesworker subjectivity this training acculturates.

\section{Work-Readiness, Labor Bravado, and the Cultivation of the Gamesworker Subjectivity}

As Ashton (2009a) notes in his analysis of game HE, industry-standard skills, corporate contacts, and work-readiness are heavily emphasized in these programs as part of their overall valuation of employability. The continued importance of this "professionalization" is no surprise as the underlying agenda within UK HE has only intensified the prioritization of preparing students for work, and both policy and promotional materials emphasize future work in the game industry as the most important element of the educational experience. The forms work-readiness approaches take, however, differ widely across institutions and programs, from industry speakers in the classroom to organized games jams, trips to conferences, and assessment activities specifically oriented towards a particular console, software, or engine (where programs have sponsorship deals with companies). While the content of these courses is therefore diverse, what is shared across these sites is the way game students are trained to view their future work lives as what Ruth S. Bridgstock and Stuart D. Cunningham (2016) call "portfolio careers," comprised of short-term contracts, project-based employment, self-employment and freelance stints, and piecemeal labor. Preparation for work entails the cultivation of this subjectivity as much as the teaching of design techniques and software, including the development of the portfolio for job application purposes as the final product of the degree. 
Games therefore resemble less the digital manufacturing sector they are positioned as by trade bodies and more the trajectory of creative workers and their career configurations hinged on flexibility/precarity, autonomy/personal risk, and passionate labor/self-exploitation. As with other creative workers, this is largely normalized and accepted (Morgan et al. 2013) by students keen to perform an entrepreneurial spirit. In response to the interview question about what worked and what did not in their degrees, I observed a hybrid expression of "venture labor" (Neff 2012), wherein precarity and self-motivated work is embraced, and the consumer ethos of getting what you pay for. Within games, the dream of a lucky break or unexpected success stories, as in the case of a second-year writing student getting hired while completing her degree, are a dominant part of the mythology of creativity and talent, and this motivates self-exploitation for workers-in-becoming. What emerges from interviews with instructors is how HEI frame themselves as part of this process, approaching students as future workers needing to develop individual responsibility in preparation for assuming the risks of economic insecurity and personal adversity in gameswork. Those who teach in these programs often exemplify the unsustainability of game careers, having come to teaching because game employment misaligned with family life, physical and mental health, or work-life balance. Instructors refer in their teaching to the myriad challenges of gameswork, including narratives of employability activities, which students then mobilize as industry norms as demonstrated by this participant:

Supposedly, because it's a relatively new industry, we have to work harder. This isn't my own analysis, I'm mostly parroting what I've heard from other people who do work in the industry. Supposedly they've had to work harder but now that's become sort of a culture. Where you're expected to stay for however many hours after your technical end of day working to get things done on time because that's just what 
people do and it becomes an expectation. That's part of it and it's not necessarily healthy. Especially crunch time. Crunch time we've been told a lot about to prepare for. Everyone loses sleep and social time and eventually you get the game done and then you have to start another game. Unless you make enough money, in which case I'm going to make tons of money. I'm going to be great. (third-year game design student, emphasis mine)

This quote demonstrates the well-rehearsed narrative of normalized exploitation within the game industry as well as a performance of labor bravado. More than an articulation of exceptionalism, such utterances encapsulate simultaneously a performed savviness about the realities of gameswork and bold assertions of sufficient talent, toughness, and willingness to sacrifice to succeed under such conditions. Affectively, there is tension underlying such labor bravado. Students in their third year and Masters programs typically declare these futures of greatness but, at present, reveal not feeling work-ready, prepared to enter the industry or indeed "the real world." Despite pervasive emphasis on employability within these programs, students feel the need for more training, time, and practice in developing their skills and abilities. This culture of anxiety is produced by a confluence of forces, not least of which is the constant messaging about managing risk students receive from agents of the neoliberal university, mediating national austerity politics and the discourses of crunch and competition from the game industry. The labor bravado of these game design students is therefore affectively and discursively contradictory, heavily informed by institutional forces that position "real world education" as partially about the embrace of precarity and uncertainty, with game HEI becoming a sort of formalized school of hard knocks. 
Discussing diversity and inclusion measures becomes a challenge when labor bravado and the embrace of do-what-you-love mythology turns into the grounds for greater conservatism, as much in terms of content of the games designed as well as approaches to work practices and cultures, rather than critique, organizing, or desire to change hegemonic practices, including a common sense "meritocratic" hiring discourse. At a brainstorming session with industry and HEI representatives, experienced game designers complained of seeing unoriginal, uncreative portfolios from recent graduates and urged instructors to encourage students to "take risks" in their gameswork. But between hefty tuition fees, frequent warnings of an oversaturated market of graduates, and horror stories about the difficulty of securing employment in the industry, it is unsurprising that students are reluctant to break with the traditions they see in gameswork and repeat familiar discourses and ideas as they prepare to enter the industry.

These case studies affirm existing research on HE and pathways into creative work, highlighting the centrality of neoliberal discourses and practices within educational policies and processes. A multitude of actions and discourses position creative and arts $\mathrm{HE}$ as a site for fostering a self-enterprising, flexible subject (Allen et al. 2013), contributing to the formation of the passionate creative worker that tolerates precarity by drawing on a personal ethic of selfreliance. We can therefore see technologies of self-governance observed within a wide range of creative industries extending into HE (Banks 2007; Gill 2010; McRobbie 2009) and in game HE specifically. The major challenge is that risk management is predominantly focused on managing one's progress through the pipeline such that other areas which may benefit from creativity, innovation, and passion, such as fostering greater inclusivity or challenging punishing work norms, are not seen as essential or even possible. Indeed, students most often performed a tolerance for and even acceptance of imposed precarious entrepreneurialism in heavily 
masculinized, aggressive terms akin to those described by Kim Allen et al. (2013). For instance, one student recounted how a particularly unapproachable instructor in his program became an object lesson in what to expect from gameswork:

I think that it's good to have someone there to give you a kick in the balls sometimes because you kind of need it because the industry isn't going to stop kicking you in the balls whenever there's an opportunity to and you just have to get used to it and you have to learn how to stand up for it and fight for yourself and fight your corner and tell people why your work's important. (Masters' student in games)

Thus the stories that might drive change instead become the basis for docile neoliberal gamesworker subjectivities celebrating the brutality of unfair and punishing industry norms, and indeed startup culture more broadly. Recognition and embrace of grim prospects presents a challenge to advocating for measures to increase diversity in games as an ethical or moral question rather than the more palatable instrumental formulation that greater diversity leads to more innovation, which subsequently produces better games. Mark Banks $(2017,42)$ outlines how "moral economy" as a concept has been used to critically analyze and evaluate the relations between economic and non-economic values, a way "to describe the ways in which ethical concerns tend to inform and shape the exercise of all kinds of economic procedures," including distribution of work. In a context where injustice is seen as not only pervasive but constitutive, intervening in HEI and creating new opportunities for marginalized groups therein based on moral arguments is difficult for many who work in these programs to imagine. Banks notes that strategies aimed at fostering creative justice, such as quotas and so-called positive discrimination, are deemed objectionable because they set social characteristics in opposition to merit. This was echoed in my conversations with students and instructors, where the association 
of diversity with innovation sat uneasily alongside the notion that even referencing the need for greater diversity was acceding to political correctness and therefore to less deserving, less talented, less meritorious pretenders (a construction familiar from the framing of casual in contrast to hardcore within game culture). Overall, the existing relative homophily in game education contributes to both the normalization of exploitative working conditions and the implicit exclusion of those already marginalized by being seen as lacking, including women, people of color, and people from working-class backgrounds.

\section{Making Interventions}

Despite the wide variations in how game creation is taught across these programs, a key similarity is the emphasis on teamwork, specifically the need for complementary specialized roles in game development. Yet, the prominence of collaborative working structures is tempered by a hyper-individualistic ethos that sets those working in temporary partnerships in opposition to each other in a competitive market of applicants to the industry. In addition to the culture detailed above, this occurs in part through the division of students according to narrowly focused roles, preparing these gamesworkers-in-becoming for the flexible specialization of the industry, along the lines of programming, design, writing, sound, art, animation, and business. Such practices in game education have two consequences, which impact inclusivity and diversity. First, as with the quote from Richard Wilson above, education appropriate for gameswork is defined as qualifications in programming and computer science, establishing a hierarchy of games specialization. The vast majority of female-identified students I interviewed were specializing in art or writing, and many noted that these skills are devalued in both the university and the industry. Secondly, the instrumentalization of teamwork as but a temporal affiliation of individuals in the process of production undermines the potential for worker solidarity and 
collective action. In this way, HEI contribute to a lack of mobilization, reaffirming the status quo of the game industry as a "terrible place to work," as one instructor characterized it.

Discussions with instructors reveals that this is in no way desirable or intended, as the vast majority of them are critical of the outcomes of structuring these programs according to the logic and culture of the industry, which rigidly defines possibilities for change, including creativity, shifting labor practices, and cultivating greater inclusivity in game-making. One instructor notes that unquestioningly constructing and conducting game program according to industry norms undermines the value and role of education, as feedback from industry guests is, in his experience, more highly regarded than that of the teachers. Irrespective of the nuance with which these instructors deliver "cautionary tales," their circulation as the grounds on which to perform labor bravado upholds rather than challenges the hegemony of play's conventional wisdom and a conservative vision of the definition of qualified developers, legitimate games, and stereotypical players.

Intervening within these norms, discourses, and resulting exclusions is no easy feat, as the attrition of those in my sample who have made attempts from within HE indicates. In the UK, where austerity-era educational policy discourse depends on notions of aspiration and meritocracy (Mendick et al. 2018), it is difficult to imagine the adoption of quotas or quantitative indicators of diversity. Existing initiatives such as the Athena SWAN equality accreditation of inclusive practices in UK HEI have not yet been pursued by any of the programs I studied, exemplifying the limits of elective measures. Promise is shown instead by the grassroots organizing of the Women in Games UK group and in particular their development of the Ambassadors program to connect those in the industry with girls in pre-university education. Through this, the not-for-profit organization engages in active recruitment in a way that common 
practices such as Open Days cannot, rewriting dominant narratives about who can make games. However, simply getting more women, people of color, or otherwise marginalized groups into an exploitative industry is not an adequate solution. For that reason, another important source of potential disruption is recent discussion about unionization at the 2018 Games Developers Conference and formation of local chapters of Game Workers Unite. The glut of workers the industry relies on to operate with crunch-related burnout and widespread early attrition is produced largely through the larger numbers of disposable workers graduating from these games HEI. Therefore, educational spaces constitute a significant site in which to raise awareness of not only unions but the idea that more humane, inclusive, and sustainable forms of gameswork are not only possible but necessary for the well-being of all involved.

\section{References}

Allen, Kim, Jocey Quinn, Sumi Hollingworth, and Anthea Rose. 2013. "Becoming Employable Students and 'Ideal' Creative Workers: Exclusion and Inequality in Higher Education Work Placements." British Journal of Sociology of Education 34 (3): 431-52.

Allen, Kim. 2013. “'What do you need to make it as a Woman in this Industry? Balls!': Female Higher Education Students 'Doing' Gender in the Cultural Industries.” In Cultural Work and Higher Education, edited by Daniel Ashton and Caitriona Noonan, 232-53. Basingstoke: Palgrave Macmillan.

Ashton, Daniel. 2009a. "Making it Professionally: Student Identity and Industry Professionals in Higher Education." Journal of Education and Work 22 (4): 283-300.

Ashton, Daniel. 2009b. “Thinking with Games: Exploring Digital Gaming Imaginaries and Values in Higher Education." Journal of Media Practice 10 (1): 57-68. 
Banks, Mark. 2007. The Politics of Cultural Work. Basingstoke: Palgrave.

Banks, Mark. 2017. Creative Justice: Cultural Industries, Work and Inequality. London: Rowman and Littlefield International.

Bridgstock, Ruth S, and Stuart D Cunningham. 2016. "Creative Labour and Graduate Outcomes: Implications for Higher Education and Cultural Policy.” International Journal of Cultural Policy 1 (10): 10-26.

Carlone, Heidi B., and Angela Johnson. 2007. "Understanding the Science Experiences of Successful Women of Color: Science Identity as an Analytic Lens." Journal of Research in Science Teaching 44 (8): 1187-1218.

Consalvo, Mia. 2007. Cheating: Gaining Advantage in Videogames. Cambridge: MIT Press.

Densham, Sophie. 2016. “10,300 now Employed in games in UK; 19\% are Women.” UKIE, 27 April. Accessed May 30, 2018. https://ukie.org.uk/news/2016/04/10300-now-employedgames-uk-19-are-women.

Deuze, Mark, Chase Bowen Martin, and Christian Allen. 2007. "The Professional Identity of Gameworkers." Convergence 13 (4): 335-53.

Fisher, Stephanie, and Alison Harvey. 2013. "Intervention for Inclusivity: Gender Politics and Indie Game Development." Loading...Journal of the Canadian Game Studies Association 7 (11): 25-40.

Fron, Janine, Tracy Fullerton, Jacquelyn Ford Morie, and Celia Pearce. 2007. "The Hegemony of Play.” Paper presented at the annual meeting of the Digital Games Research Association, Tokyo, September. 
Gill, Rosalind. 2010. “'Life is a Pitch': Managing the Self in New Media Work.” In Managing Media Work, edited by Mark Deuze, 249-60. London: Sage.

Harvey, Alison, and Tamara Shepherd. 2016. “When Passion isn't Enough: Gender, Affect and Credibility in Digital Games Design.” International Journal of Cultural Studies 20 (5): $492-508$.

Jenson, Jennifer, and Suzanne de Castell. 2013. "Tipping Points: Marginality, Misogyny, and Videogames." Journal of Curriculum Theorizing 29 (2): 72-81.

Livermore, Owen. 2013. "The Academic Grind: A Critique of Creative and Collaborative Discourses between Digital Games Industries and Post-Secondary Education in Canada.” PhD diss., University of Western Ontario, London.

McRobbie, Angela. 2009. "Reflections on Precarious Work in the Cultural Sector." In Governance der Kreativwirtschaft: Diagnosen und Handlungsoptionen [Governance of the Creative Industries: Diagnosis and Management Options], edited by Bastian Lange, Ares Kalandides, Birgit Stöber, and Ing Wellmann, 123-39. Bielefeld: Transcript Verlag.

Mendick, Heather, Kim Allen, Laura Harvey, and Aisha Ahmad. 2018. Celebrity, Aspiration and Contemporary Youth: Education and Inequality in an Era of Austerity. London: Bloomsbury.

Morgan, George, Julian Wood, and Pariece Nelligan. 2013. "Beyond the Vocational Fragments: Creative Work, Precarious Labour, and the Idea of 'Flexploitation'." The Economic and Labour Relations Review 24 (3): 397-415. 
Neff, Gina. 2012. Venture Labor: Work and the Burden of Risk in Innovation Industries. Cambridge: MIT Press.

Pettinger, Lynne, Kirsten Forkert, and Andrew Goffey. 2016. "The Promises of Creative Industry Higher Education: An Analysis of University Prospectuses in Malaysia." International Journal of Cultural Policy, DOI: 10.1080/10286632.2016.1223644.

Ramanan, Chella. 2017. "The Video Game Industry has a Diversity problem - but it can be Fixed.” The Guardian, 15 March. Accessed May 30, 2018. https://www.theguardian.com/technology/2017/mar/15/video-game-industry-diversityproblem-women-non-white-people.

Taylor, Haydn. 2018. "Exploring the Pay Gap: What does the Data really say about the Industry/s Gender Imbalance?” Gamesindustry.biz. Accessed May 30, 2018. https://www.gamesindustry.biz/articles/2018-04-05-gender-wage-gap-deep-dive.

Transfuzer. 2018. “About.” Transfuzer.com. Accessed August 9, 2018. https://tranzfuser.com/about/.

UKIE. 2015. "Student Data Sheet: Players, Diversity and Education." UKIE. Accessed May 30,2018 http://ukie.org.uk/sites/default/files/cms/docs/Diversity\%20and\%20players.pdf. 